\title{
Meeting report: Signal transduction meets systems biology
}

\author{
Christine Louis-Dit-Sully ${ }^{1 *}$, Katharina F Kubatzky ${ }^{2 *}$, Jonathan A Lindquist ${ }^{3}$, Christine Blattner ${ }^{4}$, Ottmar Janssen ${ }^{5}$ \\ and Wolfgang W A Schamel ${ }^{1,6^{*}}$
}

\begin{abstract}
In the $21^{\text {st }}$ century, systems-wide analyses of biological processes are getting more and more realistic. Especially for the in depth analysis of signal transduction pathways and networks, various approaches of systems biology are now successfully used. The EU FP7 large integrated project SYBILLA (Systems Biology of T-cell Activation in Health and Disease) coordinates such an endeavor. By using a combination of experimental data sets and computational modelling, the consortium strives for gaining a detailed and mechanistic understanding of signal transduction processes that govern T-cell activation. In order to foster the interaction between systems biologists and experimentally working groups, SYBILLA co-organized the 15th meeting "Signal Transduction: Receptors, Mediators and Genes" together with the Signal Transduction Society (STS). Thus, the annual STS conference, held from November 7 to 9, 2011 in Weimar, Germany, provided an interdisciplinary forum for research on signal transduction with a major focus on systems biology addressing signalling events in T-cells. Here we report on a selection of ongoing projects of SYBILLA and how they were discussed th this interdisciplinary conference.
\end{abstract}

\section{Introduction}

As cellular constituents of the adaptive immune system, $\mathrm{T}$ cells carry an individual $\mathrm{T}$ cell antigen receptor (TCR)/ CD3 complex with which they recognize specific antigens, resulting in activation of the cell and the mounting of an immune response [1,2]. However, to initiate a successful immune response against pathogens, without creating an inappropriate response against self-antigens, $\mathrm{T}$ cells have to discriminate between healthy cells of the body and diseased or infected cells. It is thought that the affinity of antigens to the TCR/CD3 complex governs this discrimination during intrathymic development. In the periphery, infected and diseased cells will present specific 'foreign' antigens with high affinity to the TCR leading to activation of the $\mathrm{T}$ cell. Due to the selection process,

\footnotetext{
*Correspondence: louis@immunbio.mpg.de; kubatzky@uni-heidelberg.de; schamel@immunbio.mpg.de

${ }^{1}$ Max Planck Institute of Immunobiology and Epigenetics and Biology III, Faculty of Biology, University of Freiburg, 79108, Freiburg, Germany

${ }^{2}$ Department of Infectious Diseases, Medical Microbiology and Hygiene, University Hospital of Heidelberg, Im Neuenheimer Feld 324, 69120, Heidelberg, Germany

${ }^{6}$ Center for Biological Signalling Studies BIOSS, University of Freiburg, 79104 Freiburg and Center for Chronic Immunodeficiency CCl, University Clinics, 79106, Freiburg, Germany

Full list of author information is available at the end of the article
}

peripheral self-antigens have low or no binding-affinity and should not result in T-cell activation, but might rather be involved in T-cell survival. If the multiple backup systems of central and peripheral tolerance fail, $\mathrm{T}$ cells with high affinity to self-antigens might cause autoimmunity.

T-cell activation is a complex process relying on multiple layers of tightly controlled intracellular signalling modules that form an intricate network. In order to gain systemslevel insight into critical modules of the network and finally into the behaviour of the complete network, the SYBILLA consortium was founded. It groups 18 partners from 9 different EU countries, including a management company (Novamen, Lyon, France; represented by Sandrine Rival in SYBILLA), and coordinated by Wolfgang Schamel (Freiburg, Germany). Detailed information can be found at www.sybilla-t-cell.de.

The current development of several ongoing projects has been reported at the meeting and will be described below. In essence, through a multidisciplinary effort, SYBILLA aims to understand at the systems level, how T-cells discriminate foreign from auto-antigens, how $\mathrm{T}$ cells differentiate from naive cells into effector cells and how T-cells react to auto-antigens in case of autoimmune diseases.

\section{() Biomed Central}


To meet its goals SYBILLA started with improving and standardizing new quantitative and high-throughput technologies to obtain quantitative data on signalling networks. These include multicolour immunoprecipitation measured by flow cytometry (IP-FCM) [3], with which accurate multidimensional data on protein-protein interactions and phosphorylations can be acquired. Improved mass spectrometry-based strategies were developed by Rudi Aebersold and Matthias Gstaiger (both SYBILLA in Zürich, Switzerland) for a systematic and quantitative analysis of protein interactome and phospho-proteome changes upon cell stimulation [4]. Finally, novel phosphospecific antibodies are generated by the antibodyproducing company EXBIO praha (SYBILLA near Prague, Czech Republic) [5].

Early on, SYBILLA sought to have a competent partner to exchange ideas and concepts about signal transduction processes. With the Signal Transduction Society (STS), SYBILLA found the ideal partner and has for example published the stoichiometry of the TRIM-containing TCR/CD3 in the STS journal Cell Communication and Signaling [6,7]. In 2011 SYBILLA, the STS and the Study Group Signal Transduction (AKS) of the German Society for Immunology (DGfI) (chair: Ottmar Janssen, Kiel) decided to coorganize a focus symposium on "Signaling in immune cells" at the annual STS conference "Signal Transduction Receptors, Mediators and Genes" [8,9] (Figure 1). Thus, the 2011 STS conference held in November in Weimar, Germany, set the stage for a so far unique get together of scientists working on different aspects of signal transduction that converged at the focus on T-cell activation. Here we provide a brief meeting report and - at the same time present several of SYBILLA's recent achievements.

\section{Early events in T-cell signalling}

The first element of the intracellular T-cell signalling network is the TCR/CD3 complex itself that not only recognizes the antigens but can also distinguish between low and high affinity antigens [10]. Thus, one focus of SYBILLA is to characterise and mechanistically understand the differential signal initiation by the TCR/CD3 complex. During the STS meeting in Weimar, Balbino Alarcon (SYBILLA in Madrid, Spain) presented new data showing that the proline-rich region in the cytoplasmic tail of the CD3€ subunit is crucial for $\mathrm{T}$ cell activation (Figure 2). Upon antigen-binding, this region is exposed and binds to the adaptor protein Nck $[11,12]$. His group generated mice with a mutation in the $C D 3 €$ tail, thereby preventing Nck association, and also mice with another mutation in $\mathrm{CD} 3 €$ which disables the exposure of the proline-rich region. In both cases, $\mathrm{T}$ cell functions in vivo were defective [13].

Besides structural changes in $\mathrm{CD} 3 €$, a more precise knowledge on the overall structure of TCR/CD3

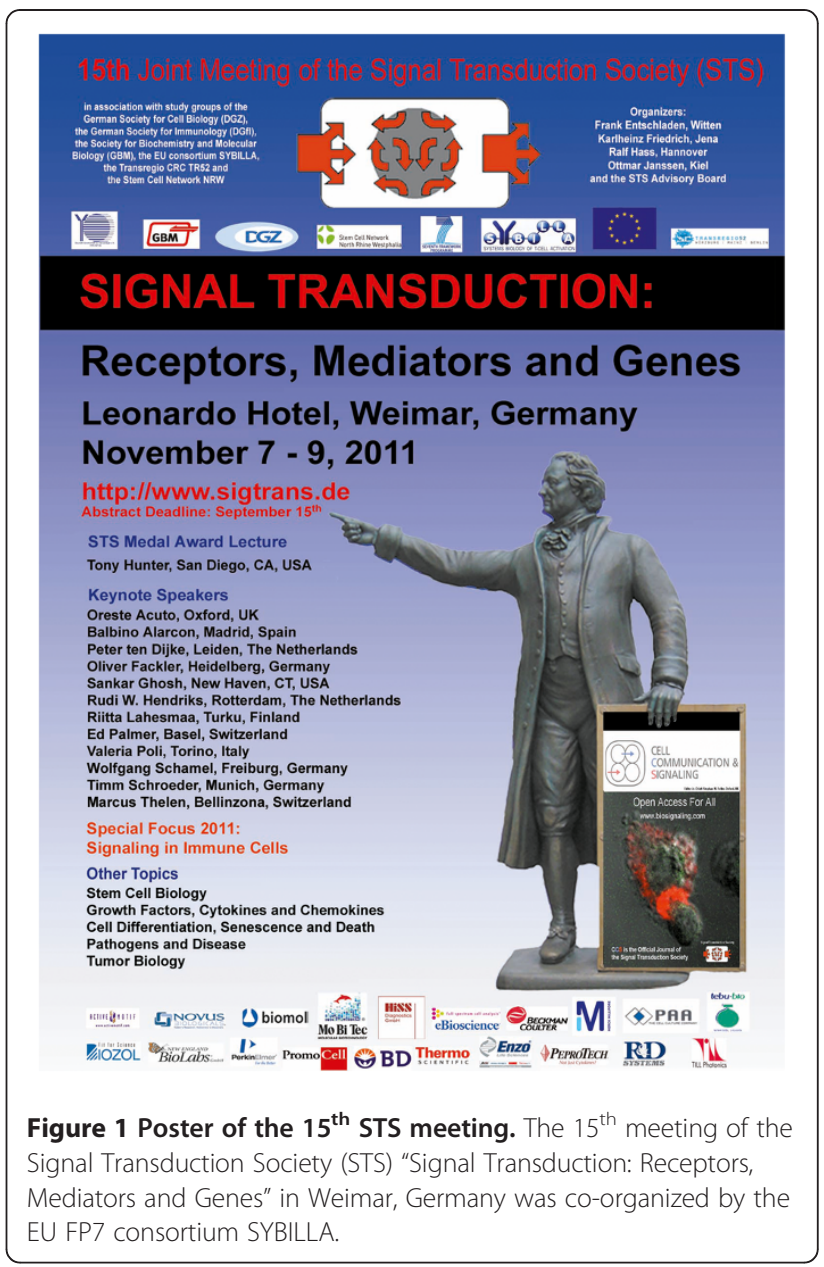

complex is crucial. Balbino Alarcon (Madrid, Spain), Wolfgang Schamel and Burkhart Schraven (SYBILLA in Magdeburg, Germany) have collaborated to decipher the stoichiometry of the TCR/CD3 $[7,14]$ and to obtain a first 3D model of the complete TCR/CD3 complex [15]. At the meeting, Wolfgang Schamel presented collaborative data with Balbino Alarcon showing that pre-clustering of the TCR/CD3 complex, which takes place independently of antigen-binding [16,17], enhances the sensitivity of Tcells [18]. Interestingly, naïve T-cells possess mostly monovalent TCR/CD3 complexes whereas effector and memory T cells express pre-clustered TCR units and therefore display lower signal thresholds and are easier to activate (Figure 2). Moreover, Schamel showed that the lipid composition of the plasma membrane is critical for TCR/CD3 pre-clustering. Lipids segregate into raft and non-raft microdomains [19-21] and raft-associated lipids are the ones that enable/cause this pre-clustering. In line with this, Tapio Lönnberg from Riitta Lahesmaa's group (SYBILLA in Turku, Finland) presented his lipidomics data showing that $\mathrm{T}$ cells change their membrane lipid composition upon differentiation from naïve to effector $T$ cells. 


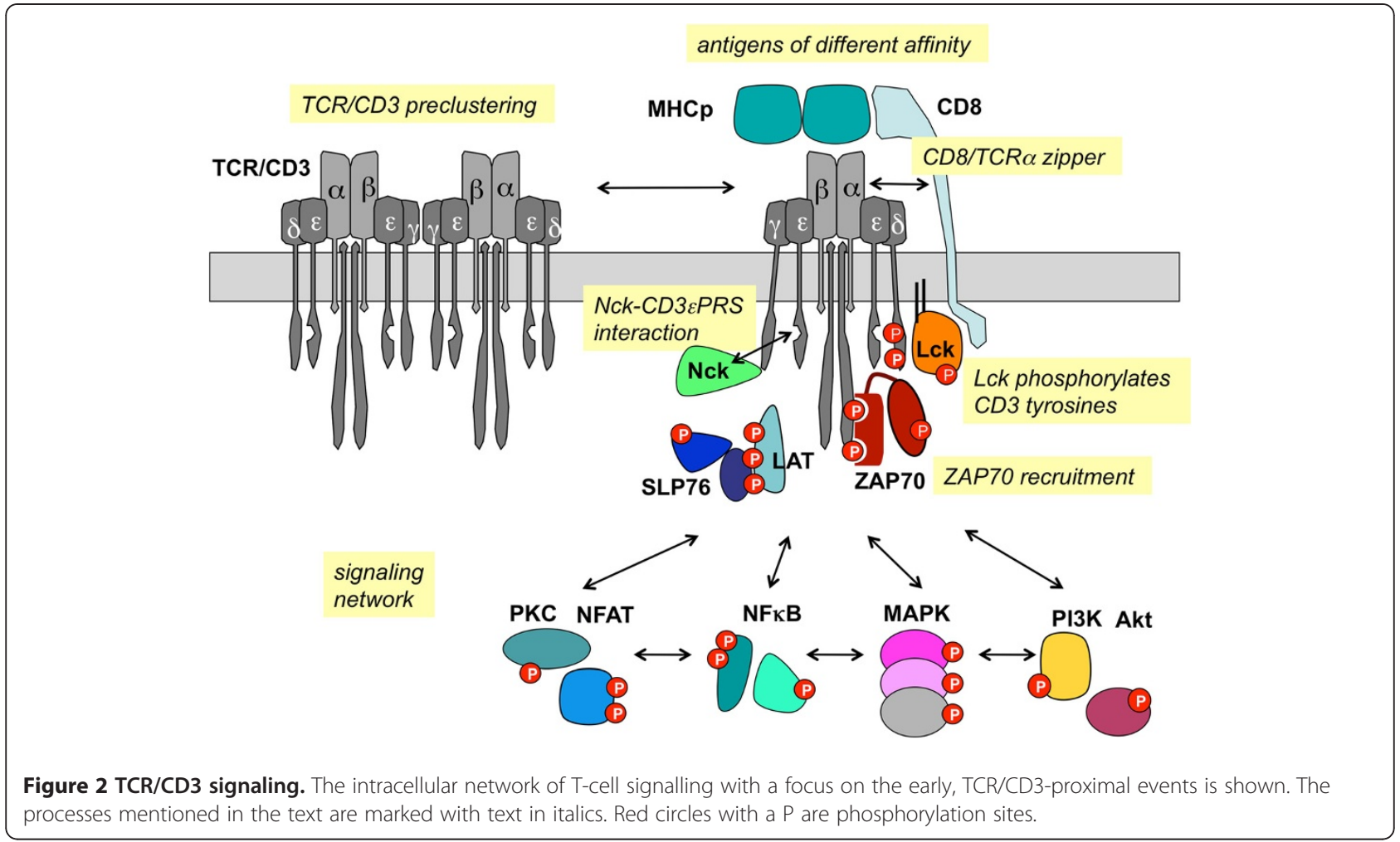

Antigen-recognition by the TCR/CD3 complex leads to the phosphorylation of tyrosines in the cytoplasmic tails of CD3. The scientist who first discovered tyrosine phosphorylation as a fundamental mechanism for signal transduction was a special guest in this year's conference. Since 2010, the STS and Cell Communication and Signaling honour researchers for outstanding contributions to signal transduction research with the "STS/CCS Honorary Medal". The first medal was awarded to Anthony J. Pawson (Toronto, Canada) in 2010 [22]. In 2011, Tony R. Hunter (La Jolla, CA, USA) was honoured for the discovery of protein tyrosine phosphorylation (Figure 3). He described during his talk how the tyrosine kinase field exploded after his initial, almost accidental, detection of phosphorylated tyrosine in Polyoma antigen immunoprecipitations in 1977 [23].

Concerning the phosphorylation of the TCR/CD3 subunits, an exciting and stimulating controversy on the activation of the tyrosine kinases Lck and Fyn, that phosphorylate CD3, is taking place within SYBILLA and became evident also at the STS conference. Burkhart Schraven showed that a subset of the kinase Lck that is associated with the TCR is activated upon TCR stimulation. This could be an important finding contributing to the understanding of how antigen binding to the TCR causes TCR phosphorylation (Figure 2). By contrast, Oreste Acuto (SYBILLA in Oxford, UK) presented data that were generated in collaboration with Antonella
Viola (SYBILLA in Milan/Padua, Italy), Thomas Höfer (SYBILLA in Heidelberg, Germany) and Lars Fugger (SYBILLA in Oxford) showing the presence of a dually phosphorylated (pY394 and pY505) and active pool of Lck even in resting T-cells [24]. In contrast to Burkhart Schraven, he proposed that Lck is not activated upon TCR/CD3 stimulation. Jonathan Lindquist (SYBILLA in Magdeburg, Germany) presented the surprising finding that PAG/Cbp-depleted human $\mathrm{T}$ cells which enhance Fyn activity (next to Lck the second Src-family kinase that can phosphorylate CD3) become anergic. This could be explained by Fyn-dependent hyper-phosphorylation of the inhibitory receptor CTLA-4. Clearly, further research is needed to clarify how antigen-binding to the TCR/CD3 causes CD3 phosphorylation.

\section{Mathematical models of early T-cell signalling}

Deciphering the mechanisms of how the TCR/CD3 complex is activated, is a starting point to understand how this receptor can distinguish between low and high affinity antigens. This needs close collaboration between experimentalists who generate quantitative data sets and applied mathematicians who use deterministic and stochastic approaches to describe those data [25-27]. Fostering those interactions is one goal of SYBILLA.

Based on the already discussed finding that antigenbinding to the TCR/CD3 complex exposes the prolinerich region in $\mathrm{CD} 3 €$ and that this exposure is necessary 


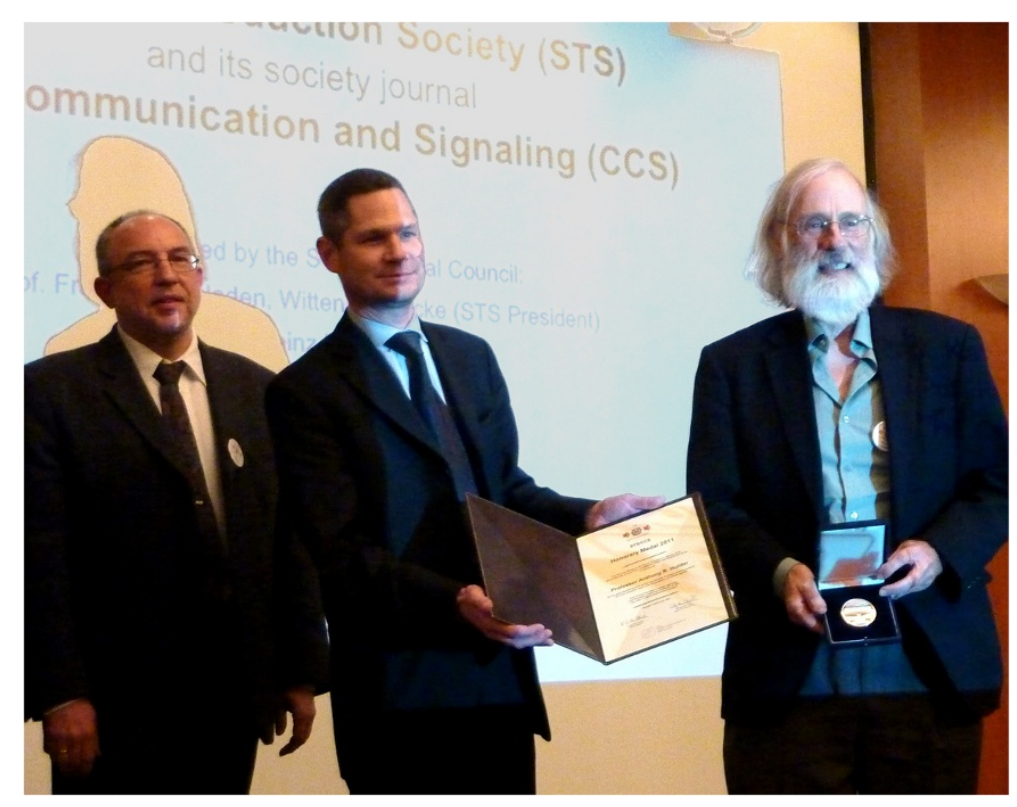

Figure 3 Tony Hunter receives the STS/CCS Honorary Medal. Since 2010 the Signal Transduction Society (STS) and Cell Communication and Signaling honour outstanding researchers in the field of signal transduction research with this medal. 2011 Tony Hunter received this award for the discovery of tyrosine phosphorylation and other important contributions in cell signaling research.

for T-cell activation [28,29], Thomas Höfer and Wolfgang Schamel have formulated a mathematical model that describes these events. The model was parametrized and validated using extensive biochemical data, such as IP-FCM (see above). Together with functional data obtained by Balbino Alarcon and Ed Palmer (SYBILLA in Basel, Switzerland), the model shows that exposure of the proline-rich region has the property to distinguish between antigens of different affinities.

T-cell antigens bind simultaneously to the TCR/CD3 complex and the co-receptor CD8. Extending this observation, Ed Palmer presented his TCR-CD8 zipper model, in which low affinity ligands bind shortly to the TCR/ CD3 and CD8, thereby not allowing CD8 to zip (bind) to the TCR/CD3 (Figure 2). High affinity ligands, however, bind longer to the TCR/CD3 complex, enabling CD8 to form a stable complex with the TCR in which the CD8-bound kinase Lck can phosphorylate TCR/CD3 subunits and initiate signaling [30]. This model belongs to the kinetic proofreading models [31], in which the duration of the antigen-TCR/CD3 interaction determines the outcome.

Finally, Anna Schulze (from Thomas Höfer's group) presented a new mathematical model of TCR/CD3 phosphorylation and ZAP70 recruitment (Figure 2) that was based on IP-FCM data generated by Wolfgang Schamel's group [3]. These accurate time-resolved data allowed for the first time the quantitative determination of phosphorylation and dephosphorylation rate constants in the mathematical model, indicating very rapid turnover of both ITAM and ZAP-70 phosphorylations. In contrast to the previous proposal that multiple phosphorylations at the TCR complex kinetically proofread ligand quality (see e.g. [25][31]), the actual parameter values indicate that such a mechanism can only play a minor role in ligand discrimination.

\section{Holistic views on T-cell activation}

Besides the TCR/CD3 and associated kinases, the LAT/ SLP76 signalosome (Figure 2) is examined in detail within SYBILLA by Oreste Acuto and Bernard Malissen (SYBILLA in Marseille, France). This topic was not covered at the conference and thus, we would like to refer to the literature $[32,33]$. The PKC/NFAT module is studied by Gottfried Baier (SYBILLA in Innsbruck, Austria). Natascha Hermann-Kleiter of his group reported on the NR2F6 receptor that specifically dampens NFATmediated IL-17a promoter activation in CD4 $\mathrm{T}$ lymphocytes. Dysregulation of this mechanism seems to play a role in the development of certain autoimmune diseases [34]. Another important pathway for T-cell activation is the NF- $\mathrm{kB}$ pathway that was covered in the conference by several talks (Figure 2). Sankar Ghosh (New York, NY, USA) was invited by the Transregional Collaborative Research Center TR52 "Transcriptional Programming of Individual T-Cell Subsets" (chair: Edgar Serfling, Würzburg, Germany) and gave an introductory keynote lecture in which he discussed the role of NF- $\mathrm{kB}$ as a molecular switch of lymphocyte development and functions. In particular, he suggested that PDK1 is a 
scaffold for PKC $\theta$ and Carma1, contributing to NF-kB activation. Rebecca Breuer (Heidelberg, Germany) reported about the phosphatase PP2R5C that controls NF- $\kappa \mathrm{B}$ activation and Sarah Jill de Jong (Erlangen, Germany) showed that the viral oncogene Tio also controls T-cell NF- $\mathrm{B}$ signaling.

Next to detailed research on early signalling, comprehensive understanding of the complete T-cell signalling network is another objective of SYBILLA. This is mostly done by transcriptomic and phospho-proteomic analyses with subsequent description by dynamic models.

The importance of using high-through-put methods to understand molecular mechanisms was highlighted at the conference by SYBILLA partner, Riitta Lahesmaa (SYBILLA in Turku, Finland) with a talk on 'Highthrough-put biology to understand molecular mechansims of human T helper cell differentiation'. She reported the transcriptional regulation of lymphocyte activation and differentiation. Applying a holistic approach, she profiled gene expression during Th2 cell differentiation. Bioinformatic description of the data by Harri Lähdesmäki (SYBILLA in Turku, Finland) have led to novel hypotheses on the key factors involved in human Th2 cell differentiation. After IL-4 stimulation, STAT6 is needed for the regulation of gene expression controlling human Th2 cell differentiation [35]. In another talk, Yuri Shebzukhov (Berlin, Germany) showed data indicating less active Jnk (a MAP kinase) and concomitantly less cJun phosphorylation in Th0 and Th2 cells compared to Th1 and Th17.

The transcriptomics data, provided by Riitta Lahesmaa, will be integrated with phospho-proteome and interactome data, generated within SYBILLA by Bernard Malissen (who has generated knock-in mice for this purpose), Rudi Aebersold and Matthias Gstaiger as well as Oreste Acuto. Signalling network behaviour is studied in primary murine and human $\mathrm{T}$ cells in healthy states and is then extended to autoimmune disease models such as multiple sclerosis with Lars Fugger (SYBILLA in Oxford), Pablo Villoslada (SYBILLA in Barcelona, Spain) and diabetes with Arno Hanninen (SYBILLA in Turku, Finland). Finally, spacial data by Antonella Viola's group complement these approaches [36].

A future goal is the generation of a "virtual T-cell"; an in silico simulation of T-cell activation. Such efforts should help to refine the predictability of physiological and pathophysiological outcomes, as well as to identify new biological markers and new drug targets. For this purpose, a Boolean network of the T-cell signalling network generated by Burkhart Schraven and Jonathan Lindquist [37] is regularly updated within SYBILLA. Indeed, the network was recently extended to integrate signalling through the IL-2 receptor (Figure 4) [38]. Looking for specific therapeutic targets for autoimmune diseases, Friederike
Berberich-Siebelt (Würzburg, Germany) suggested some specific roles of SUMOylation of NFAT proteins in multiple sclerosis, while Lucas Kemper from Hansjörg Hauser's group (Braunschweig, Germany) presented an IFN reporter mouse model showing fast $\mathrm{T}$ cell responses to type I IFN in lymphoid tissue. Knowing reported negative effects of type I IFN on T cells, it was surprising not to find alterations in $\mathrm{T}$ cell signalling by investigating the endpoints of important signalling cascades (NFAT, NFkB, AP-1).

As mentioned earlier, $\mathrm{T}$ cells are of course also the effector cells of the adaptive immune system. Ottmar Janssen recently characterized the proteome composition of intact effector vesicles from $\mathrm{T}$ and NK cells [39-41]. His team identified two morphologically distinct species of cytotoxic effector granulae in $\mathrm{T}$ cells characterized by a differential abundance of effector molecules including FasL and granzymes or perforin [42]. Although these vesicles may belong to a common multivesicular body, it appears that they utilize distinct cytoskeletal-associated transport systems for their activation-dependent mobilization to the immunological synapse.

\section{Intracellular signalling in non-T cells}

The strong focus on T-cell signalling of the STS Meeting 2011 was balanced by presentations on signalling events in other cell types. This nicely complemented the otherwise too narrow focus for such a medium-sized international conference.

B-cell signalling was introduced in a keynote talk by Rudi Hendriks (Rotterdam, Netherlands; presentation sponsored by the AKS of the DGfI). He focused on the role of the adaptor protein SLP65, which is a crucial intracellular signal transducer for B cell signaling. Malfunctions of SLP65 can cause immunodeficiencies as well as B cell tumours. Niklas Engels (Göttingen, Germany) identified a tyrosine-based signalling motif within the cytoplasmic tail of the IgG heavy chain, that upon stimulation becomes phosphorylated by Syk and recruits Grb2 to enhance PLC $\gamma$ activation and calcium flux. New findings on the role of NFATc1 for B cell receptor (BCR)/CD40-triggered proliferation of naive $\mathrm{B}$ cells was reported by Anh Thuy Duong Pham (Würzburg, Germany). Using mice with an inactive NFATc1 gene in bone marrow cells and with subsequent conditional reexpression of NFATc1 in NFATc $1^{-/-}$B cells, she was able to show that NFATc1 supports proliferation after BCR- or CD40-stimulation and that it suppresses the activation-induced cell death of splenic B cells.

Signaling in myeloid cells was addressed by two talks. Thomas Hochdörfer (Aachen, Germany) showed that in mast cells the Cbl-interacting protein CIN85 interacts with SHIP, thereby regulating extent and kinetics of antigen-triggered FceR1 internalization. Christopher 


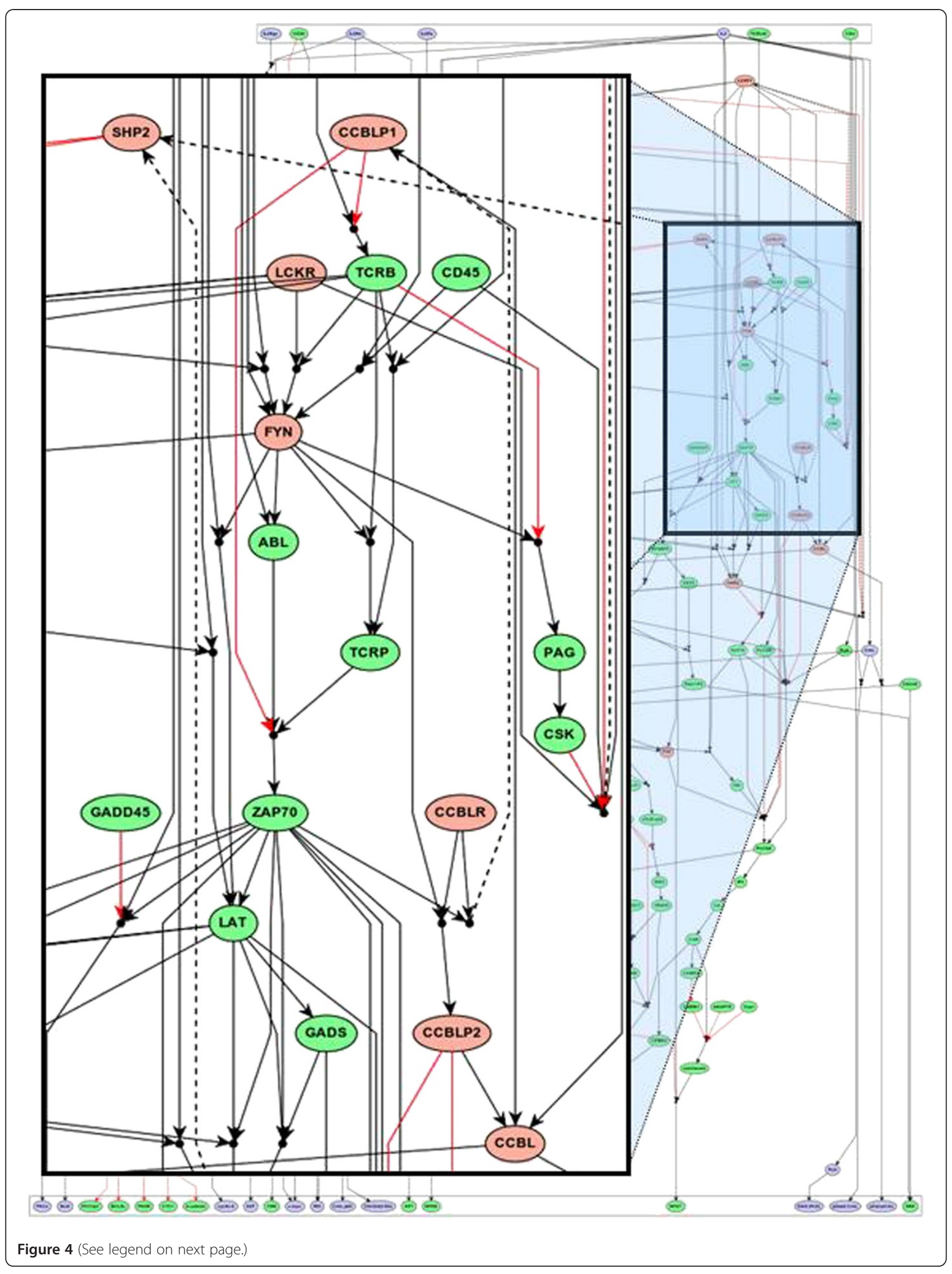


(See figure on previous page.)

Figure 4 The merged TCR and IL-2R signaling network. The top layer represents input nodes and the bottom layer outputs, i.e. molecules including transcription factors that become activated. Solid black arrows indicate activating interactions with black circles denoting ANDconnections. For clarity, activating influences with arrows pointing from the bottom to the top are drawn with dashed black lines. Red lines mark inhibitory interactions that are expressed as NOT-conditions in the logical network. Nodes specific to the IL-2R and TCR network are shown in blue and green, respectively. Common nodes are depicted in red. The insert shows a magnified region of the network. Further details can be found in [38].

Tiedje (Hannover, Germany) used macrophages to reveal that p38 (a MAP Kinase)-mediated phosphorylation of an AU-rich element binding factor, TTP, silences TNF $\alpha$ mRNA specifically when translated at the ER. Veronika Jahndel (Heidelberg, Germany) who is investigating how apoptotic cells induce tolerogenic dendritic cells (DCs), identified annexin A1 as an early apoptotic marker on lymphocytes. She could show that annexin A1 interferes with Toll-like receptor signaling, thereby preventing NF-kB activation and DC maturation.

Using a reconstituted system, Iris Behrmann (Luxemburg City, Luxemburg) demonstrated that downstream of the common $\gamma$ chain, which for example is part of the IL2-R, Jak 1 has a dominant role over Jak3, even though data on Jak3 deficiency had predicted the opposite [43].

\section{Mechanisms of signal transduction}

The STS Meetings traditionally provide a broad and interdisciplinary view on a variety of cellular and organismic signalling aspects, which intentionally provokes to view cellular signalling from different angles and to establish new connections and networks within the community. The topics presented as Workshops included mechanisms of signal transduction in cancer cells, host pathogen interactions, receptor-related studies as well as various aspects of cell fate decisions in immune and cancer cells.

The workshop "Tumor Biology" covered aspects ranging from signalling studies to screening approaches and pharmacologic studies. In her keynote lecture, Valeria Poli (Turin, Italy) discussed functions of the signal transducer and activator of transcription (STAT) 3 protein in inflammation and cancer and the relevance of its subcellular localization for cancer-related signalling events [44]. Arnd Kieser (Munich, Germany) reported on the development of an ELISA-based screen to identify inhibitors of the interaction between viral and cellular signalling molecules and Felix Hausch (Munich, Germany) showed that the interaction of larger FK506-binding proteins with rapamycin contributes to its pharmacological effects. Using a guided clustering approach Alexandra Schrader (Göttingen, Germany) showed data on gene expression modules in Burkitt lymphoma cells. Stephan Feller (Oxford, UK) presented a method that allows the generation of kinome deregulation profiles of cancer cells by label-free quantitative high-throughput mass spectrometry [45] and phosphoproteome analyses by other more conventional techniques.

The workshop "Pathogens and Disease" discussed the role of various viral and bacterial factors in the regulation of signalling cascades in immune cells. A common theme among viral immune evasion strategies is the manipulation of transcription factors or regulators of the actin cytoskeleton such as Rho GTPases. This was nicely illustrated in Oliver Fackler's (Heidelberg, Germany) keynote talk on the subversion of TCR signal transduction by HIV-1 [46]. As viruses depend on the activity and the survival of their host cell, viral proteins can induce cancer through excess proliferative signals [47]. An example presented by Kristin Katsch (Erlangen, Germany) is the interaction of the transcription factor SRF with the co-factor protein Mal in T cells that can be triggered by overexpression of the viral oncoprotein Tip through Tip-induced Rho GTPase activation. Another viral regulator of host transcriptional processes is Tax-1, encoded by human $\mathrm{T}$ cell lymphotrophic virus type-1 (HTLV-1). Andrea Kress (Erlangen, Germany) showed that it induces the expression of the tumor marker fascin and that this is a common mechanism among viral oncogenes of lymphotrophic viruses [48]. Bacterial factors, however, are also able to modulate the signalling pathways of their host cells and thus modify the resulting immune response. Dagmar Hildebrand (Heidelberg, Germany) discussed how the Pasteurella multocida protein toxin manipulates cells to produce the proinflammatory cytokine IL-1 $\beta$ independently from inflammasome-mediated activation of Caspase-1, a wellcharacterized pathway described for other pathogens [49]. Bernd Schmeck (Marburg, Germany) highlighted in his talk the fact that the expression of small, non-coding RNAs (miRNA) that are able to repress specific target genes [50] plays an important role for the expression of Legionella pneumophila-induced induction of proinflammatory genes and that TLR-receptor-induced signalling cascades are important components in the regulation of miRNA expression [51].

The workshop "Growth Factors, Cytokines and Chemokines" started with a review by Marcus Thelen's (Bellinzona, Switzerland) on signalling events triggered by atypical chemokine receptors that do not bind to heterotrimeric $\mathrm{G}$ proteins [52]. A common theme among the following talks was the control of cell cycle 
progression. Katja Handschick (Giessen, Germany) presented data on the effects of a constitutively active cyclindependent kinase 6 (CDK6) mutant in non-synchronised HeLa cells. With this and other approaches, she could show that gene expression induced by IL-1/TNF $\alpha$ utilises classical cell cycle-regulated pathways. Malte Kriegs (Hamburg, Germany) presented data on the different molecular mechanism of cell cycle arrest in tumor cells induced by radiation or pharmacological EGF receptor inhibitors. These inhibitors have the capacity to enhance the radiation-induced, persistent G1 arrest cells. Thus, inhibition of EGFR, a known key-player in cancer [53] is a promising target for therapeutical sensitisation of tumours displaying an intact p53 pathway after X-ray treatment [54]. Sandip Kar (Heidelberg, Germany) explained that not only qualitative but also quantitative aspects of signalling pathways have an influence on the outcome of cellular signalling. He was able to show that the differential activation of the PI3K/Akt pathway in response to stimulation with erythropoietin can be explained by the different expression levels of PI3K/Akt pathway components, such as the phosphatases SHIP-1 and PTEN.

The last workshop of the conference addressed the topic "Cell Differentiation, Senescence and Death". Keynote speakers of this session were Timm Schroeder (Munich, Germany) and Peter ten Dijke (Leiden, Netherlands). In his talk, Timm Schroeder impressively demonstrated the importance of single cell, real-time analysis for the investigation of signal transduction pathway activity or the differentiation activity of stem cells [55]. Peter ten Dijke summarised the role of TGF $\beta$ signal transduction pathways in cancer [56]. FRET experiments done by Simon Neumann (Stuttgart, Germany) showed that TNF-related apoptosis-inducing ligand (TRAIL) receptors can form heteromeric receptor complexes in the absence of ligand. The group of Ingo Schmitz (Braunschweig, Germany) investigated the expression of the transcription factor Foxp3 which is essential for the development of regulatory $\mathrm{T}$ cells (Tregs). They could show that the atypical $\mathrm{NF}_{\kappa} \mathrm{B}$ inhibitor IkB $\mathrm{B}_{\mathrm{NS}}$ plays an important role in Foxp3 gene transcription and in the absence of $\mathrm{I} K \mathrm{~B}_{\mathrm{NS}}$ only a reduced number of Tregs is generated. For his presentation, Ingo Schmitz was awarded the STS Science Award 2012 sponsored by Biomol GmbH, Hamburg. Björn Stork (Düsseldorf, Germany) finished the session with a talk on the factors Atg13 and FIP200 that can support the induction of cellular autophagy also independently of Ulk1 and Ulk2 kinases under basal and starvation conditions [57].

One special highlight of the STS meetings that deserves mentioning is the traditional "One Minute One Transparency" session where virtually all posters were presented to the plenum to trigger the following poster viewing and discussion. Once again in 2011, this fun event certainly lowered the thresholds to establishing new networks - this time not short-lived signalling networks but rather longer term scientific networks.

\section{Acknowledgements}

First of all we thank the organizers and co-organisors of the 2011 STS conference "Signal Transduction: Receptors, Mediators and Genes", which include the STS Council and Advisory Board, the whole SYBILLA consortium, the TR52 and the Signalling Study Groups of the German Societies for Immunology (DGfl) and Cell Biology (DGZ) and the Society for Biochemistry and Molecular Biology (GBM). We also acknowledge the help of J. Wienands (Göttingen), F. Berberich-Siebelt and E. Serfling (Würzburg), F. Entschladen and T. Dittmar (Witten-Herdecke), H. Ungefroren (Lübeck) and Stephan Feller (Oxford) in the preparation of the manuscript.

This work was funded by the DFG through the SFB620, SCHA 976/2-1, BMBF 01 EO 0803 and by the EU through FP7/2007-2013 (SYBILLA) to CLDS, JAL and WWS (Figure 5).

\section{Author details}

'Max Planck Institute of Immunobiology and Epigenetics and Biology III, Faculty of Biology, University of Freiburg, 79108, Freiburg, Germany. ${ }^{2}$ Department of Infectious Diseases, Medical Microbiology and Hygiene, University Hospital of Heidelberg, Im Neuenheimer Feld 324, 69120, Heidelberg, Germany. ${ }^{3}$ Institute of Molecular and Clinical Immunology, Otto-von-Guericke University, Leipziger Strasse 44, 39120, Magdeburg, Germany. ${ }^{4}$ Karlsruhe Institute of Toxicology and Genetics, PO-Box 364076021 , Karlsruhe, Germany. ${ }^{5}$ Christian-Albrechts-University of Kiel, Institute for Immunology, UKSH Campus Kiel, Arnold-Heller-Str. 3 Bldg 17, 24105, Kiel, Germany. ${ }^{6}$ Center for Biological Signalling Studies BIOSS, University of Freiburg, 79104 Freiburg and Center for Chronic Immunodeficiency CCI, University Clinics, 79106, Freiburg, Germany.
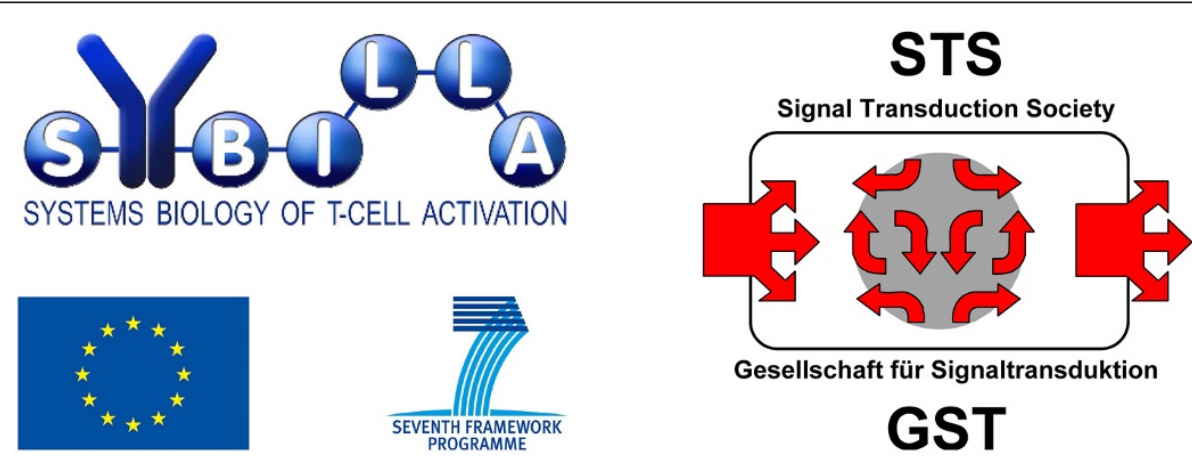

Figure 5 The conference was mainly supported and organized by the EU FP7 consortium SYBILLA (Systemsbiology of T-cell activation) and STS (The Signal Transduction Society). 
Received: 1 March 2012 Accepted: 7 April 2012

Published: 30 April 2012

\section{References}

1. Malissen B: An evolutionary and structural perspective on T cell antigen receptor function. Immunol Rev 2003, 191:7-27.

2. Alarcon B, Gil D, Delgado P, Schamel WWA: Initiation of TCR signaling: regulation within CD3 dimers. Immunol Rev 2003, 191:38-46.

3. Deswal S, Schulze AK, Hofer T, Schamel WW: Quantitative analysis of protein phosphorylations and interactions by multi-colour IP-FCM as an input for kinetic modelling of signalling networks. PLoS One 2011, 6:e22928.

4. Wepf A, Glatter T, Schmidt A, Aebersold R, Gstaiger M: Quantitative interaction proteomics using mass spectrometry. Nat Methods 2009, 6:203-205.

5. Dopfer EP, Schopf B, Louis-Dit-Sully C, Dengler E, Hohne K, Klescova A, Prouza M, Suchanek M, Reth M, Schamel WW: Analysis of novel phospho-ITAM specific antibodies in a S2 reconstitution system for TCR-CD3 signalling. Immunol Lett 2010, 130:43-50.

6. Feller SM, Hass R, Janssen O, Friedrich K: Cell Communication and Signaling is becoming the official journal of the Signal Transduction Society. Cell Commun Signal 2008, 6:1

7. Swamy M, Siegers GM, Fiala GJ, Molnar E, Dopfer EP, Fisch P, Schraven B, Schamel WW: Stoichiometry and intracellular fate of TRIM-containing TCR complexes. Cell Commun Signal 2010, 8:5

8. 12th Joint Meeting of the Signal Transduction Society (STS). Signal Transduction: Receptors, Mediators and Genes Weimar, Germany. 29-31 October 2008. Abstracts. Cell Commun Signal 2009, 7 Suppl 1:A1-A108.

9. Entschladen F, Altschmied J, Baumgrass R, Behrmann I, Giehl K, Hermanns H, Huber O, Kieser A, Klotz LO, Kubatzky KF, et al: Signal transduction, receptors, mediators and genes: younger than ever - the 13th meeting of the Signal Transduction Society focused on aging and immunology. Cell Commun Signal 2010, 8:2.

10. Davis MM, Boniface JJ, Reich Z, Lyons D, Hampl J, Arden B, Chien Y: Ligand recognition by alpha/beta T cell receptors. Annu Rev Immunol 1998, 16:523-544

11. Lettau M, Pieper J, Janssen O: Nck adapter proteins: functional versatility in T cells. Cell Commun Signal 2009, 7:1.

12. Gil D, Schamel WW, Montoya M, Sanchez-Madrid F, Alarcon B: Recruitment of Nck by $\mathrm{CD} 3$ epsilon reveals a ligand-induced conformational change essential for T cell receptor signaling and synapse formation. Cell 2002, 109:901-912.

13. Martinez-Martin N, Risueno RM, Morreale A, Zaldivar I, Fernandez-Arenas E, Herranz F, Ortiz AR, Alarcon B: Cooperativity between T cell receptor complexes revealed by conformational mutants of CD3epsilon. Sci Signal 2009, 2:ra43.

14. Swamy M, Dopfer EP, Molnar E, Alarcon B, Schamel WW: The 450 kDa TCR Complex has a Stoichiometry of abgedezz. Scand J Immunol 2008 67:418-420. author reply 421

15. Arechaga I, Swamy M, Abia D, Schamel WA, Alarcon B, Valpuesta JM: Structural characterization of the TCR complex by electron microscopy. Int Immunol 2010, 22:897-903.

16. Schamel WW, Arechaga I, Risueno RM, van Santen HM, Cabezas P, Risco C, Valpuesta JM, Alarcon B: Coexistence of multivalent and monovalent TCRs explains high sensitivity and wide range of response. J Exp Med 2005, 202:493-503.

17. Lillemeier BF, Mortelmaier MA, Forstner MB, Huppa JB, Groves JT, Davis MM: TCR and Lat are expressed on separate protein islands on T cell membranes and concatenate during activation. Nat Immunol 2010, 11:90-96.

18. Kumar R, Ferez M, Swamy M, Arechaga I, Rejas MT, Valpuesta JM, Schamel WW, Alarcon B, van Santen HM: Increased sensitivity of antigenexperienced T cells through the enrichment of oligomeric T cell receptor complexes. Immunity 2011, 35:375-387.

19. Simons K, Toomre D: Lipid rafts and signal transduction. Nat Rev Mol Cell Biol 2000, 1:31-39.

20. Harder T, Sangani D: Plasma membrane rafts engaged in T cell signalling: new developments in an old concept. Cell Commun Signal 2009, 7:21.

21. Kennedy C, Nelson MD, Bamezai AK: Analysis of Detergent-free Lipid Rafts isolated from a CD4+ T cell line: Interaction with antigen presenting cells promotes coalescing of lipid rafts. Cell Commun Signal 2011, 9:31.
22. Feller SM: First Honorary Medal of the Signal Transduction Society (STS) and 'CELL COMMUNICATION AND SIGNALING' awarded to Professor Anthony J. (Tony) Pawson. Cell Commun Signal 2011, 9:3.

23. Eckhart W, Hutchinson MA, Hunter T: An activity phosphorylating tyrosine in polyoma T antigen immunoprecipitates. Cell 1979, 18:925-933.

24. Nika K, Soldani C, Salek M, Paster W, Gray A, Etzensperger R, Fugger L, Polzella P, Cerundolo V, Dushek O, et al: Constitutively active Lck kinase in T cells drives antigen receptor signal transduction. Immunity 2010, 32:766-777.

25. Kobayashi H, Azuma R, Yasunaga T: Expression of excess receptors and negative feedback control of signal pathways are required for rapid activation and prompt cessation of signal transduction. Cell Commun Signal 2009, 7:3

26. Altan-Bonnet $\mathrm{G}$, Germain RN: Modeling T cell antigen discrimination based on feedback control of digital ERK responses. PLOS Biol 2005, 3:e356.

27. Dushek O, Aleksic M, Wheeler RJ, Zhang H, Cordoba SP, Peng YC, Chen JL, Cerundolo V, Dong T, Coombs D, van der Merwe PA: Antigen potency and maximal efficacy reveal a mechanism of efficient $T$ cell activation. Sci Signal 2011, 4:ra39.

28. Risueno RM, Schamel WW, Alarcon B: T cell receptor engagement triggers its CD3epsilon and CD3zeta subunits to adopt a compact, locked conformation. PLoS One 2008, 3:e1747.

29. Minguet S, Swamy M, Alarcon B, Luescher IF, Schamel WW: Full activation of the $T$ cell receptor requires both clustering and conformational changes at CD3. Immunity 2007, 26:43-54.

30. Palmer $E$, Naeher $D$ : Affinity threshold for thymic selection through a T-cell receptor-co-receptor zipper. Nat Rev Immunol 2009, 9:207-213.

31. McKeithan TW: Kinetic proofreading in T-cell receptor signal transduction. Proc Natl Acad Sci U S A 1995, 92:5042-5046.

32. Mingueneau M, Roncagalli R, Gregoire C, Kissenpfennig A, Miazek A, Archambaud C, Wang Y, Perrin P, Bertosio E, Sansoni A, et al: Loss of the LAT adaptor converts antigen-responsive $T$ cells into pathogenic effectors that function independently of the T cell receptor. Immunity 2009, 31:197-208.

33. Gruber T, Hermann-Kleiter N, Hinterleitner R, Fresser F, Schneider R, Gastl G, Penninger JM, Baier G: PKC-theta modulates the strength of T cell responses by targeting Cbl-b for ubiquitination and degradation. Sci Signal 2009, 2:ra30

34. Hermann-Kleiter N, Gruber T, Lutz-Nicoladoni C, Thuille N, Fresser F, Labi V, Schiefermeier N, Warnecke M, Huber L, Villunger A, et al: The nuclear orphan receptor NR2F6 suppresses lymphocyte activation and T helper 17-dependent autoimmunity. Immunity 2008, 29:205-216.

35. Elo LL, Jarvenpaa H, Tuomela S, Raghav S, Ahlfors H, Laurila K, Gupta B, Lund RJ, Tahvanainen J, Hawkins RD, et al: Genome-wide profiling of interleukin-4 and STAT6 transcription factor regulation of human Th2 cell programming. Immunity 2010, 32:852-862.

36. Contento RL, Campello S, Trovato AE, Magrini E, Anselmi F, Viola A: Adhesion shapes T cells for prompt and sustained T-cell receptor signalling. Embo J 2010, 29:4035-4047.

37. Saez-Rodriguez J, Simeoni L, Lindquist JA, Hemenway R, Bommhardt U, Arndt B, Haus UU, Weismantel R, Gilles ED, Klamt S, Schraven B: A logical model provides insights into T cell receptor signaling. PLoS Comput Biol 2007, 3:e163.

38. Beyer T, Busse M, Hristov K, Gurbiel S, Smida M, Haus UU, Ballerstein K Pfeuffer F, Weismantel R, Schraven B, Lindquist JA: Integrating signals from the T-cell receptor and the interleukin-2 receptor. PLOS Comput Biol 2011, 7:e1002121.

39. Schmidt H, Gelhaus C, Nebendahl M, Lettau M, Watzl C, Kabelitz D, Leippe M, Janssen O: 2-D DIGE analyses of enriched secretory lysosomes reveal heterogeneous profiles of functionally relevant proteins in leukemic and activated human NK cells. Proteomics 2008, 8:2911-2925.

40. Schmidt H, Gelhaus C, Nebendahl M, Lettau M, Lucius R, Leippe M, Kabelitz D, Janssen O: Effector granules in human T lymphocytes: the luminal proteome of secretory lysosomes from human T cells. Cell Commun Signal 2011, 9:4.

41. Schmidt H, Gelhaus C, Lucius R, Nebendahl M, Leippe M, Janssen O: Enrichment and analysis of secretory lysosomes from lymphocyte populations. BMC Immunol 2009, 10:41.

42. Schmidt H, Gelhaus C, Nebendahl M, Lettau M, Lucius R, Leippe M, Kabelitz D, Janssen O: Effector granules in human T lymphocytes: proteomic evidence for two distinct species of cytotoxic effector vesicles. J Proteome Res 2011, 10:1603-1620 
43. Haan C, Rolvering C, Raulf F, Kapp M, Druckes P, Thoma G, Behrmann I, Zerwes HG: Jak1 has a dominant role over Jak3 in signal transduction through gammac-containing cytokine receptors. Chem Biol 2011, 18:314-323.

44. Demaria M, Poli V: From the nucleus to the mitochondria and back: the odyssey of a multitask STAT3. Cell Cycle 2011, 10:3221-3222.

45. Wu Z, Doondeea JB, Gholami AM, Janning MC, Lemeer S, Kramer K, Eccles SA, Gollin SM, Grenman R, Walch A, et al: Quantitative chemical proteomics reveals new potential drug targets in head and neck cancer. Mol Cell Proteomics 2011, 10:M111 011635.

46. Pan X, Rudolph JM, Abraham L, Habermann A, Haller C, Krijnse-Locker J, Fackler OT: HIV-1 Nef compensates for disorganization of the immunological synapse by inducing trans-Golgi network-associated Lck signaling. Blood 2012, 119:786-797.

47. McLaughlin-Drubin ME, Munger K: Viruses associated with human cancer. Biochim Biophys Acta 2008, 1782:127-150.

48. Kress AK, Kalmer M, Rowan AG, Grassmann R, Fleckenstein B: The tumor marker Fascin is strongly induced by the Tax oncoprotein of HTLV-1 through NF-kappaB signals. Blood 2011, 117:3609-3612.

49. Muller A, Oertli M, Arnold IC: H. pylori exploits and manipulates innate and adaptive immune cell signaling pathways to establish persistent infection. Cell Commun Signal 2011, 9:25.

50. Davis BN, Hata A: Regulation of MicroRNA Biogenesis: A miRiad of mechanisms. Cell Commun Signal 2009, 7:18.

51. O'Neill LA, Sheedy FJ, McCoy CE: MicroRNAs: the fine-tuners of Toll-like receptor signalling. Nat Rev Immunol 2011, 11:163-175.

52. Thelen M, Stein JV: How chemokines invite leukocytes to dance. Nat Immunol 2008, 9:953-959.

53. Seufferlein T, Ahn J, Krndija D, Lother U, Adler G, von Wichert G: Tumor biology and cancer therapy - an evolving relationship. Cell Commun Signal 2009, 7:19.

54. Wang M, Morsbach F, Sander D, Gheorghiu L, Nanda A, Benes C, Kriegs M, Krause M, Dikomey E, Baumann M, et al: EGF receptor inhibition radiosensitizes NSCLC cells by inducing senescence in cells sustaining DNA double-strand breaks. Cancer Res 2011, 71:6261-6269.

55. Schroeder T: Long-term single-cell imaging of mammalian stem cells. Nat Methods 2011, 8:S30-35.

56. Meulmeester E, Ten Dijke P: The dynamic roles of TGF-beta in cancer. J Pathol 2011, 223:205-218.

57. Alers S, Löffler AS, Paasch F, Dieterle AM, Keppeler H, Lauber K, Campbell DG, Fehrenbacher B, Schaller M, Wesselborg S, Stork B: Atg13 and FIP200 act independently of Ulk1 and Ulk2 in autophagy induction. Autophagy 2011, 7:Epub ahead of print.

doi:10.1186/1478-811X-10-11

Cite this article as: Louis-Dit-Sully et al:: Meeting report: Signal transduction meets systems biology. Cell Communication and Signaling 2012 10:11.

\section{Submit your next manuscript to BioMed Central and take full advantage of:}

- Convenient online submission

- Thorough peer review

- No space constraints or color figure charges

- Immediate publication on acceptance

- Inclusion in PubMed, CAS, Scopus and Google Scholar

- Research which is freely available for redistribution 